NASA Technical Memorandum 104497

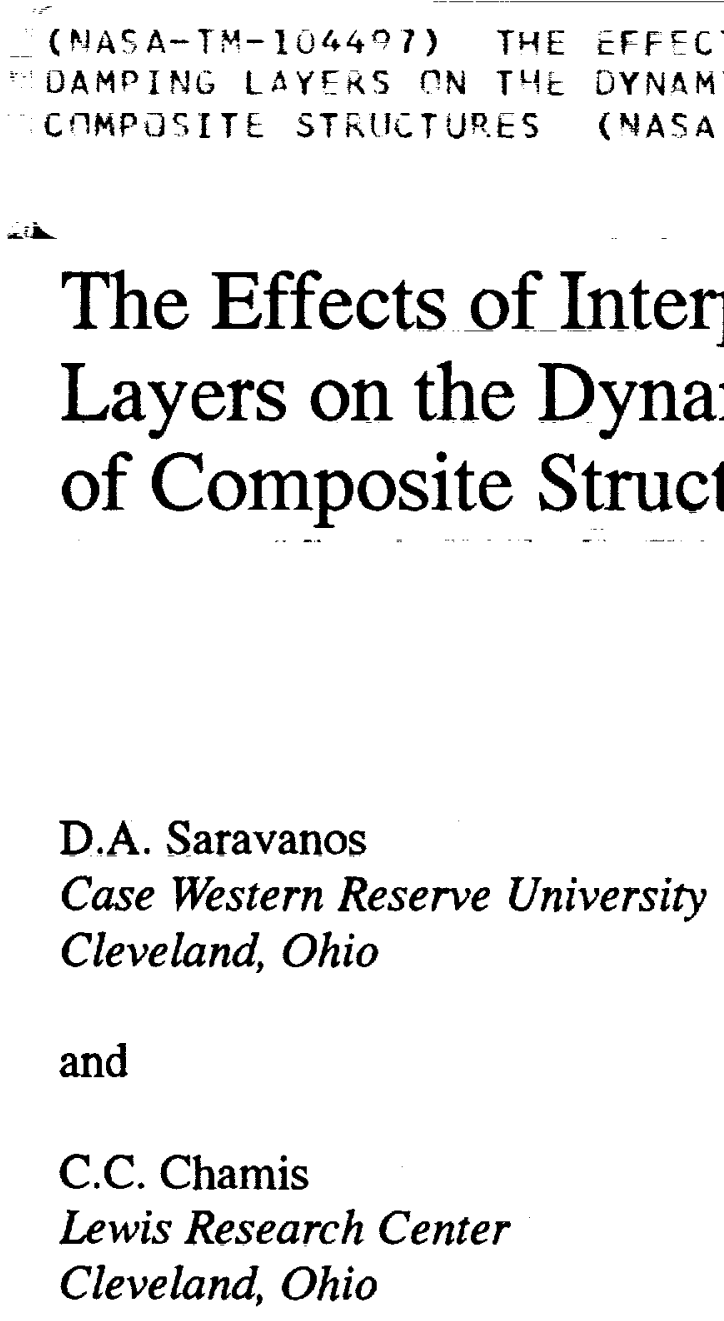

\section{$1 N-24$}

N91-30292

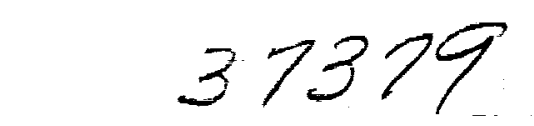

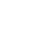




$$
\leq \quad \therefore
$$




\title{
THE EFFECTS OF INTERPLY DAMPING LAYERS ON THE DYNAMIC \\ RESPONSE OF COMPOSITE STRUCTURES
}

\author{
D.A. Saravanos* \\ Case Western Reserve University \\ Cleveland, Ohio 44106 \\ and \\ C.C. Chamis \\ National Aeronautics and Space Administration \\ Lewis Research Center \\ Cleveland, Ohio 44135
}

\begin{abstract}
Integrated damping mechanics for composite laminates with constrained interlaminar layers of polymer damping materials are developed. Discrete layer damping mechanics are presented for composite laminates with damping layers, in connection with a semi-analytical method for predicting the modal damping in simply-supported specialty composite plates. Several application cases are used to demonstrate the advantages of the method. Damping predictions for graphite/epoxy composite plates of various laminations demonstrate the potential for higher damping than geometrically equivalent aluminum plates. The effects of aspect ratio, damping layer thickness, and fiber volume ratio on static and dynamic characteristics of the composite plate are also investigated.
\end{abstract}

\footnotetext{
"Resident Research Associate at NASA Lewis Research Center.
} 


\section{Introduction}

Damping is a significant dynamic parameter for vibration and sound control, dynamic stability, positioning accuracy, fatigue endurance, and impact resistance. Many current structural applications (for example large space structures, engine blades, high speed machinery) require light-weight and high dynamic performance. Therefore, candidate sources of passive damping should add minimal parasitic weight and be compatible with the structural configuration.

Two potential damping sources satisfying the previous requirements are the constrained damping layer approach, and the damping capacity of composites. Constrained damping layers in isotropic metallic structures have been widely applied and investigated ${ }^{1}$. They provide high damping, but tend to increase the structural weight and offer limited means for damping tailoring. The inherent damping capacity of composite materials also seems promising. Although the damping of composite structures is not very high, it is significantly higher than most common metallic structures. Moreover, composites are the materials of preference in many cases, as they readily provide high specific stiffness and strength. More importantly, research on the damping mechanics of composite laminates ${ }^{2-4}$ and structures ${ }^{5,6}$ has shown that composite damping is anisotropic, highly tailorable, and depends on an array of micromechanical, laminate, and structural parameters. It has been further demonstrated that optimal tailoring may significantly improve the damped dynamic performance of composite structures ${ }^{7}$.

It seems likely that the combination of both approaches, that is, composite structures with interlaminar damping layers will offer the advantages of high damping, damping tailoring, good mechanical properties, and low weight addition. In addition, the interlaminar damping concept is highly compatible with the laminated configuration of composite structures and 
their fabrication techniques. Contrary to isotropic materials, the variations in anisotropy and elastic properties of each composite ply typically induce high interlaminar stresses, hence, interlaminar layers may produce higher and also tailorable damping. However, other critical mechanical properties, such as stiffness and strength, are expected to be reduced. In view of the complexity of the problem, it is very desirable to develop integrated composite mechanics that will efficiently predict the damping of composite structures with interlaminar damping layers, together with other critical mechanical properties and dynamic characteristics. Limited analytical and experimental work has been reported in this direction, including the damping of specialty composite truss members in extensional deformation ${ }^{8-10}$, and the damping analysis of simple composite beams using continuum finite element simulations ${ }^{11,12}$.

This paper presents recent developments on integrated damping mechanics for composite laminates with interlaminar damping layers. The laminate mechanics are general, in that they incorporate the capability for arbitrary numbers of plies and damping layers, arbitrary fiber orientations, and arbitrary fiber volume ratios (FVRs). They also include the capacity to simulate the damping of extensional, bending, and coupled deformations. The theory assumes a general piecewise continuous displacement field through the thickness of the laminate. The damping mechanics for composite laminates with damping layers is also integrated with other composite mechanics theories ${ }^{13,14}$, in order to include the effects of the many composite parameters on the dynamic characteristics.

Finally, a semi-analytical methodology for the prediction of the dynamic properties of simplysupported (SS) specialty thick composite plates with interlaminar damping layers is developed. Results regarding the modal damping values, natural frequencies and static deflections of $\mathrm{Gr} /$ Epoxy composite plates are presented. The effects of various cross-ply configurations, aspect ratio, damping layer thickness, and FVR on the damped dynamic characteristics are investigated. 


\section{Method}

This section first reviews the synthesis of the composite properties for each composite ply and interlaminar layer. Then the developed damping mechanics for composite laminates with interply layers (Fig 1a), and the dynamic analysis of specialty composite plates with interlaminar damping layers are presented.

\section{Composite Properties}

For a unidirectional composite loaded along the material axes, closed-form expressions have been developed for the synthesis of elastic and dissipative properties ${ }^{13,14}$. Five independent elastic parameters completely characterize the stiffness of a unidirectional composite (orthotropic but transversely isotropic material): in-plane longitudinal modulus $\mathrm{E}_{111}$, transverse in-plane modulus $E_{122}$, in-plane Poisson's ratio $\nu_{112}$, in-plane shear modulus $G_{112}$, and interlaminar shear modulus $\mathrm{G}_{123}$. Additionally, four independent damping coefficients characterize the damping capacity, that is, longitudinal specific damping capacity (SDC) $\psi_{11}$ (direction 11), transverse in-plane damping $\psi_{12}$ (direction 22), transverse through-thethickness damping $\psi_{13}=\psi_{12}$ (direction 33), in-plane shear damping $\psi_{16}$ (direction 12), interlaminar shear damping $\psi_{14}$ (direction 23), and interlaminar shear damping $\psi_{15}=\psi_{16}$ (direction 13). The specific damping capacities (SDCs) and elastic properties are explicitly related to fiber/matrix properties (ref. 14), and the fiber volume ratio (FVR).

The interlaminar layers are assumed isotropic. Two independent elastic properties (Young's modulus and Poisson's ratio) and two independent damping properties (normal and shear SDC's) completely characterize their viscoelastic behavior.

\section{Off-Axis Composites}


For the case of off-axis composites, ie. composites loaded at an angle $\theta$, the following transformations provide the stiffness matrix $\left[\mathrm{E}_{\mathrm{c}}\right]$ and the damping capacity matrix $\left[\psi_{c}\right]$ respectively ${ }^{13,14}$.

$$
\begin{aligned}
& {\left[E_{c}\right]=[R]^{-1}\left[E_{l}\right][R]^{-T}} \\
& {\left[\psi_{c}\right]=[R]^{T}\left[\psi_{l}\right][R]^{-T}}
\end{aligned}
$$

$\left[E_{l}\right]$ is the stiffness matrix of the composite in the material coordinate system, and $\left[\psi_{1}\right]$ represents the on-axis composite damping. The transformation matrix [R] and the damping matrices $\left[\psi_{1}\right]$ and $\left[\psi_{c}\right]$ are shown in the Appendix.

Each interlaminar layer is treated as an isotropic material, hence, the above eqs. are reduced to trivial cases. In this manner, and contrary to many reported studies involving simplifying assumptions, all independent elastic and dissipative properties of the composite plies and the interlaminar laminae are considered.

\section{Laminates with Interlaminar Damping Layers}

To model the damping of laminates with interlaminar damping layers, a discrete layer laminate damping theory (DLDT) incorporating a piecewise continuous displacement field through-the-thickness is developed. Compared to other laminate theories based on assumed continuous displacement fields, the DLDT provides the capacity for more accurate strain and dissipative energy calculations in each ply, and particularly in each damping layer. The kinematic assumptions for the laminate theory are schematically shown in Fig $1 \mathrm{~b}$. Discrete layer theories were originally proposed by Grigolyuk and were subsequently generalized by other researchers (see ref. 15) for the more accurate calculation of stresses in thick laminates. However, with additional development the DLDT combines the potential for 
accurate damping predictions in composite laminates with damping layers, while maintaining generality and elegance. The assumed displacement field has the form,

$$
\begin{aligned}
& u(x, y, z, t)=u^{o}(x, y, t)+\bar{u}(x, y, z, t) \\
& v(x, y, z, t)=v^{o}(x, y, t)+\bar{v}(x, y, z, t) \\
& w(x, y, z, t)=w^{o}(x, y, t)
\end{aligned}
$$

where superscript $o$ represents the uniform through-the-thickness midplane deflection. Assuming that the displacements are separable functions of $z$, as suggested by Reddy and co-workers ${ }^{16}$, the previous eqs. take the form:

$$
\begin{aligned}
& u(x, y, z, t)=u^{o}(x, y, t)+\sum_{j=1}^{N} u^{j}(x, y, t) F^{j}(z) \\
& v(x, y, z, t)=v^{o}(x, y, t)+\sum_{j=1}^{N} v^{j}(x, y, t) F^{j}(z) \\
& w(x, y, z, t)=w^{o}(x, y, t)
\end{aligned}
$$

where, $u^{j}$ and $v^{j}$ are displacements, along the $x$ and $y$ directions respectively, preferably at the interfaces between composite plies or sublaminates (group of plies) and the interlaminar damping layers. $F^{\mathrm{j}}(\mathrm{z})$ are interpolation functions. In this manner, the assumed in-plane displacement field is general, in that it may represent extensional, flexural, shear, and coupled deformations, as well as, the interlaminar shear strains through-the-thickness of the laminate.

The laminate strains are directly derived from eqs. (4)

$$
\begin{array}{ll}
\epsilon_{c i}=\epsilon_{c i}^{o}+\sum_{j=1}^{N} \epsilon_{c i}^{j} F^{j}(z) & i=1,2,6 \\
\epsilon_{c i}=\epsilon_{c i}^{o}+\sum_{j=1}^{N} \epsilon_{c i}^{j} F_{z}^{j}(z) & i=4,5
\end{array}
$$


where, the midplane strains are,

$$
\begin{array}{lll}
\epsilon_{c 1}^{o}=u_{x}^{o} & \epsilon_{c 2}^{o}=v_{y}^{o} & \epsilon_{c 6}^{o}=u_{y}^{o}+v_{x x}^{o} \\
\epsilon_{c 4}^{o}=w_{y}^{o} & \epsilon_{c 5}^{o}=w_{x}^{o} &
\end{array}
$$

and the generalized strains are,

$$
\begin{array}{lll}
\epsilon_{c 1}^{j}=u_{x}^{j} & \epsilon_{c 2}^{j}=v_{y}^{j} & \epsilon_{c 6}^{j}=u_{y}^{j}+v_{x}^{j} \\
\epsilon_{c 4}^{j}=v^{j} & \epsilon_{c 5}^{j}=u^{j} &
\end{array}
$$

the comma in the subscripts indicates differentiation.

The dissipated strain energy per unit area of the laminate $\Delta w_{L}$ is,

$$
\Delta w_{L}=1 / 2 \int_{-h / 2}^{h / 2} \epsilon_{c}^{T}\left[E_{c}\right]\left[\psi_{c}\right] \epsilon_{c} d z
$$

Combination of eqs. $(8,5-7)$ ultimately provides the dissipated strain energy per unit area,

$$
\Delta w_{L}=1 / 2\left(\epsilon_{c}^{o T}\left[A_{d}\right] \epsilon_{c}^{o}+2 \epsilon_{c}^{o T} \sum_{j=1}^{N}\left[B_{d}^{j}\right] \epsilon_{c}^{j}+\sum_{j=1}^{N} \sum_{m=1}^{N} \epsilon_{c}^{j T}\left[D_{d}^{j m}\right] \epsilon_{c}^{m}\right)
$$

where, $\left[A_{d}\right]$ is the extensional laminate damping matrix, including out-of-plane shear terms. The generalized coupling damping matrices $\left[\mathrm{B}_{d}{ }^{j}\right]$ and flexural/shear matrices $\left[\mathrm{D}_{d}{ }^{j \mathrm{~m}}\right]$ are new. 


$$
\begin{array}{rlr}
{\left[A_{d}\right]} & =\sum_{k=1}^{N_{l}} \int_{h_{\underline{k}-1}}^{h_{\underline{k}}}\left[E_{c}\right]_{k}\left[\psi_{c}\right]_{k} d z & \\
\left(B_{d}^{j}\right)_{i n} & =\sum_{k=1}^{N_{l}} \int_{h_{\underline{k}-1}}^{h_{\underline{k}}}\left(\left[E_{c}\right]_{k}\left[\psi_{c}\right]_{k}\right)_{i n} F^{j}(z) d z & \\
\left(B_{d}^{j}\right)_{i n} & =\sum_{k=1}^{N_{l}} \int_{h_{\underline{k}-1}}^{h_{\underline{k}}}\left(\left[E_{c}\right]_{k}\left[\psi_{c}\right]_{k}\right)_{i n} F_{z}^{j}(z) d z & \\
\left(D_{d}^{j m}\right)_{i n}= & \sum_{k=1}^{N_{l}} \int_{h_{\underline{k}-1}}^{h_{\underline{k}}}\left(\left[E_{c}\right]_{k}\left[\psi_{c}\right]_{k}\right)_{i n} F^{j}(z) F^{m}(z) d z & \\
\left(D_{d}^{j m}\right)_{i n}= & \sum_{k=1}^{N_{l}} \int_{h_{\underline{k}-1}}^{h_{\underline{k}}}\left(\left[E_{c}\right]_{k}\left[\psi_{c}\right]_{k}\right)_{i n} F_{z}^{j}(z) F_{z}^{m}(z) d z &
\end{array}
$$

Similarly the maximum laminate strain energy per unit area $w_{L}$ is by definition,

$$
w_{L}=1 / 2 \int_{-h / 2}^{h / 2} \epsilon_{c}^{T}\left[E_{c}\right] \epsilon_{c} d z
$$

Combination of eqs. $(11,5-7)$ provides the maximum strain energy as a separable form of material properties and strains,

$$
w_{L}=1 / 2\left(\epsilon_{c}^{o T}[A] \epsilon_{c}^{o}+2 \epsilon_{c}^{o T} \sum_{j=1}^{N}\left[B^{j}\right] \epsilon_{c}^{j}+\sum_{j=1}^{N} \sum_{m=1}^{N} \epsilon_{c}^{j T}\left[D^{j m}\right] \epsilon_{c}^{m}\right)
$$

where, $[\mathrm{A}]$ is the extensional laminate stiffness matrix, with additional out-of-plane shear terms. The generalized coupling stiffness matrices $\left[\mathrm{B}^{\mathrm{j}}\right]$ and flexural/shear matrices $\left[\mathrm{D}^{\mathrm{jm}}\right]$ are new. 


$$
\begin{array}{rlr}
{[A]} & =\sum_{k=1}^{N_{l}} \int_{h_{\underline{k}-1}}^{h_{\underline{k}}}\left[E_{c}\right]_{k} d z & \\
\left(B^{j}\right)_{i n} & =\sum_{k=1}^{N_{l}} \int_{h_{\underline{k}-1}}^{h_{\underline{k}}}\left(\left[E_{c}\right]_{k}\right)_{i n} F^{j}(z) d z & \\
\left(B^{j}\right)_{i n} & =\sum_{k=1}^{N_{l}} \int_{h_{\underline{k}-1}}^{h_{\underline{k}}}\left(\left[E_{c}\right]_{k}\right)_{i n} F_{, z}^{j}(z) d z & \\
\left(D^{j m}\right)_{i n}= & \sum_{k=1}^{N_{l}} \int_{h_{\underline{k}-l}}^{h_{\underline{k}}}\left(\left[E_{c}\right]_{k}\right)_{i n} F^{j}(z) F^{m}(z) d z & \\
\left(D^{j m}\right)_{i n}= & \sum_{k=1}^{N_{l}} \int_{h_{\underline{k}-1}}^{h_{\underline{k}}}\left(\left[E_{c}\right]_{k}\right)_{i n} F_{, z}^{j}(z) F_{, z}^{m}(z) d z & \\
\end{array}
$$

The equivalent laminate specific damping capacity for a given local displacement field is:

$$
\psi_{L}=\Delta w_{L} / w_{L}
$$

In both eqs. (10) and (13), the interlaminar damping layers are considered as individual plies having isotropic elastic and damping matrices $\left[\mathrm{E}_{\mathrm{c}}\right]$ and $\left[\psi_{\mathrm{c}}\right]$ respectively. For a given interlaminar layer, $\left[\psi_{\mathrm{c}}\right]$ is determined from the mechanical properties of the material as a trivial composite case (ref. [14]). In this manner, the proposed laminate damping mechanics are general, as they can handle any number of composite plies, damping layers, and laminate configurations. 


\section{Simply-Supported Composite Plates}

The damped dynamic characteristics of simply supported specialty composite plates with interlaminar damping layers are calculated based on the previously described discrete-layer laminate damping theory. As will be shown in the remaining section, in the special case of composite plates consisting of 0 and 90 degrees plies, exact semi-analytical modal analysis solutions exist. Hence, exact and computationally inexpensive predictions of static and dynamic characteristics (modal damping, natural frequencies) are possible which will provide valuable insight in the mechanics of the problem and will establish the critical parameters. Most other laminations, boundary conditions, and structural configurations require approximate solutions, and such methods will be presented in the near future.

Assuming a rectangular $\alpha$ by $\beta$ symmetric composite plate with negligible coupling $\left(\mathrm{A}_{16}=\right.$ $A_{26}=0, B_{16}^{j}=B_{26}^{j}=0, D^{j m}{ }_{16}=D^{j m}{ }_{26}=0$ ), the following Navier fundamental solutions form a complete set of mode shapes in the $\mathrm{x}$-y plane:

$$
\begin{aligned}
u_{m n}^{o}(x, y, t) & =U_{m n}^{o} \cos (a x) \sin (b y) e^{i \omega t} \\
v_{m n}^{o}(x, y, t) & =V_{m n}^{o} \sin (a x) \cos (b y) e^{i \omega t} \\
w_{m n}^{o}(x, y, t) & =W_{m n}^{o} \sin (a x) \sin (b y) e^{i \omega t} \\
u_{m n}^{j}(x, y, t) & =U_{m n}^{j} \cos (a x) \sin (b y) e^{i \omega t} \\
v_{m n}^{j}(x, y, t) & =V_{m n}^{j} \sin (a x) \cos (b y) e^{i \omega t}
\end{aligned}
$$

Where, $a=m \pi / \alpha$ and $b=n \pi / \beta$. Combination of eqs. $(6,7,15)$ yields the modal mid-plane and generalized strains as separable functions of $x, y$ coordinates, time, and amplitudes.

$$
\left\{\epsilon^{o}\right\}_{m n}=\left[B_{m n}^{o}\right]\left\{U_{m n}^{o}\right\} e^{i \omega t} \quad\left\{e^{j}\right\}_{m n}=\left[B_{m n}^{j}\right]\left\{U_{m n}^{j}\right\} e^{i \omega t}
$$

where, the terms in matrices $[\mathrm{B}]_{\mathrm{mn}}$ are sine/cosine functions of $\mathrm{x}, \mathrm{y}$ coordinates and mode order. The amplitude displacement vectors are $U^{\circ}=\left\{U^{\circ}, V^{o}, W^{o}\right\}^{T}$ and $U^{j}=\left\{U^{j}, V^{j}\right\}^{T}$. The 
kinetic energy through the thickness of the plate is:

$$
K_{L}=1 / 2 \int_{-h / 2}^{h / 2}\{\dot{u}\}^{T} \rho\{\dot{u}\} d z
$$

Considering eqs. (4) the laminate kinetic energy per unit area takes the form:

$$
K_{L}=1 / 2\left(\left\{\dot{u}^{o}\right\}^{T}\left[A_{M}\right]\left\{\dot{u}^{o}\right\}+2\left\{\dot{u}^{o}\right\}^{T} \sum_{j=1}^{N}\left[B_{M}^{j}\right]\left\{\dot{u}^{j}\right\}+\sum_{j=1}^{N} \sum_{m=1}^{N}\left\{\dot{u}^{j}\right\}^{T}\left[D_{M}^{j m}\right]\left\{\dot{u}^{m}\right\}\right.
$$

where the generalized laminate mass and inertia matrices are

$$
\begin{aligned}
{\left[A_{M}\right] } & =\sum_{k=1}^{N_{l}} \int_{h_{\underline{\underline{k}}-1}}^{h_{\underline{k}}} \operatorname{diag}\left(\rho_{k}\right) d z \\
{\left[B_{M}^{j}\right] } & =\sum_{k=1}^{N_{l}} \int_{h_{\underline{k}-1}}^{h_{\underline{k}}} \operatorname{diag}\left(\rho_{k}\right) F^{j}(z) d z \\
{\left[D_{M}^{j m}\right] } & =\sum_{k=1}^{N_{l}} \int_{h_{\underline{k}-1}}^{h_{\underline{k}}} \operatorname{diag}\left(\rho_{k}\right) F^{j}(z) F^{m}(z) d z
\end{aligned}
$$

The term $\operatorname{diag}\left(\rho_{\mathrm{k}}\right)$ indicates a diagonal matrix, with all diagonal terms equal to the density of the k-th ply.

By substituting eqs. (16) into the strain and kinetic energy expressions for the laminate, eqs. (12) and (18) respectively, integrating over the plate area, and applying Lagrangian dynamics, it can be proved that the undamped modal analysis (free vibration) solution of the plate takes the form:

$$
-\omega_{m n}^{2}\left[M_{m n}\right] U_{m n}+\left[K_{m n}\right] U_{m n}=0
$$

where, the through-the-thickness modal displacements are $\left\{\mathbf{U}_{m n}\right\}=\left\{\mathbf{U}_{\mathrm{omn}} ; \mathbf{U}_{\mathbf{1 m n}}, \ldots, \mathbf{U}_{\mathrm{Nmn}}\right\}$ and subscripts $\mathrm{m}, \mathrm{n}$ indicate the mode order. Numerical solution of this eigenvalue problem provides the natural frequencies $\omega_{m n}$ and the through-the-thickness modes $\left\{\mathbf{U}_{m n}\right\}$ for each 
order mn of plane modes, in the context of eqs. (15).

The modal SDC associated with the $\mathrm{n}$-th vibration mode $\psi_{\mathrm{n}}$ is:

$$
\psi_{n}=\frac{\int_{V} \Delta w_{n} d V}{\int_{V} w_{n} d V}
$$

where $\Delta w_{n}$ and $w_{n}$ represent the dissipated and maximum specific modal strain energies per cycle respectively. For laminated composite plates the modal damping becomes, where $\Delta w_{\mathrm{Ln}}$

$$
\psi_{n}=\frac{\int_{A} \Delta w_{L n} d A}{\int_{A} w_{L n} d A}
$$

and $w_{\mathrm{Ln}}$ are respectively the dissipated and maximum laminate modal strain energies of the n-th mode. To calculate the modal damping, eqs. (10) and (13) are integrated through-thethickness, and are combined with eqs. (9) and (12) respectively. Then the generalized stresses and strains are related to the calculated mode shape using eq. (16). The integrations over the area of the plate are performed analytically. Since the natural frequencies and the mode shapes through-the-thickness are calculated numerically from eq. (20), the whole procedure is semi-analytical. 


\section{Applications and Discussion}

This section presents applications of the developed methodology on square laminated Gr/epoxy simply-supported (SS) plates with interlaminar damping layers. The dimensions of the plate were assumed 11.8 in by 11.8 in. The composite material was HM-S graphite/epoxy with elastic and damping properties given in ref. 6. Unless otherwise stated, the fiber volume ratio (FVR) of the composite plies will be 0.50 . The shear modulus and shear SDC of the interlaminar damping layer were $0.9 \mathrm{kpsi}$ and 6.4 respectively, and represent measured values of a typical commercial damping polymer ${ }^{17}$ at room temperature. Experimental data regarding the normal SDC of the damping polymer was not available, in part because their contributions are considered negligible. Hence, a low normal SDC $(0.10)$ was assumed. The Poisson's ratio of the damping polymer was assumed equal to 0.3 . The effects of frequency on the properties of the damping polymer were neglected. The nominal thickness $t_{i}$ of the damping layer was equal to the typical thickness of a composite ply $t_{1}=0.005$ in. In all cases a concentrated vertical load of $100 \mathrm{lbs}$ was applied at the center of the plate. Linear interpolation functions $\mathrm{F}^{\mathrm{j}}(\mathrm{z})$ were used to calculate the in-plane displacements through-thethickness of the laminate.

The ply-stacking sequence is represented using the traditional convention, but an interlaminar damping layer of thickness $t_{i}$ is identified with symbol $i$. For comparison purposes, calculated results for aluminum plates are also presented, in such case, an aluminum layer of thickness equal to the thickness of $\mathrm{k}$ plies will be identified as $\mathrm{Al}_{\mathbf{k}}$. All laminate configurations were symmetric.

Predicted modal SDCs, natural frequencies, and static deflections at the center of an aluminum $\left(\mathrm{Al}_{4} / \mathrm{i} / \mathrm{Al}_{4}\right) \mathrm{s}$ and various $\mathrm{Gr} / \mathrm{epoxy}$ damped plates, $\left(0_{4} / \mathrm{i} / \mathrm{O}_{4}\right) \mathrm{s},\left(0_{4} / \mathrm{i} / 90_{4}\right) \mathrm{s}$ and $\left(0_{2} / 90_{2} / \mathrm{i} / \mathrm{O}_{2} / 90_{2}\right)$ s are shown in Table 1 . All plates have high modal damping values. The 
laminates with the higher anisotropy in the composite sublaminates, ie. $\left(0_{4} / \mathrm{i} / 0_{4}\right) \mathrm{s}$ and $\left(0_{4} / \mathrm{i} / 90_{4}\right)$ s, exhibit the higher damping in the fundamental mode. The $\left(0_{4} / \mathrm{i} / 90_{4}\right)$ s laminate exhibits the higher anisotropy variation through-the-thickness among all plates, and this seems to contribute to higher modal damping. Interestingly, this laminate has comparable static stiffness and natural frequency with the $\left(0_{2} / 90_{2} / \mathrm{i} / \mathrm{O}_{2} / 90_{2}\right)$ s laminate, which illustrates a possibility for higher damping values without significantly penalizing other structural characteristics. The high damping of the unidirectional composite laminate was attributed in part to the lower stiffness of the plate. The composite plates have higher static deflections but lower areal density than the aluminum plate, as a result, they exhibit slightly higher fundamental frequencies. The damping of the higher modes varies widely and depends on the respective mode shape. The variation is more predominant for the composite plates.

The variations of the first modal damping, natural frequency, and static deflection at the center of the plate are plotted in Fig. 2 as functions of the damping layer thickness. The thickness of the composite sublaminates was kept constant, therefore, the total laminate thickness was varied. The layer thickness $t_{i}$ is normalized by the nominal ply thickness $t_{1}=$ 0.005 in. The modal SDC is also normalized by the shear SDC of the polymer, and will be referred in the next paragraphs as normalized modal damping. For layer thicknesses in the range of practical interest, the laminate with the higher anisotropy through-the-thickness $\left(0_{4} / \mathrm{i} / 90_{4}\right)$ s provides consistently higher damping than the aluminum $\left(\mathrm{Al}_{4} / \mathrm{i} / \mathrm{Al}_{4}\right) \mathrm{s}$ and $\left(0_{2} / 90_{2} / \mathrm{i} / \mathrm{O}_{2} / 90_{2}\right) \mathrm{s}$ laminates. This results are consistent with the expectation that composite laminates will induce higher interlaminar shear stresses in the interlaminar layer, in-order to balance the elastic anisotropy and nonuniformity of adjacent plies, as opposed to traditional isotropic laminates where interlaminar stresses will only balance the bending stresses through-the-thickness. For all laminates, the modal damping increased with thickness and tends to reach a maximum at higher thickness values. It was observed that for plates of lower aspect ratio $a / h$ the peak in the modal damping shifts towards lower thicknesses. 
Finally, it seems that a critical damping layer thickness exists (in this case approximately equal to the ply thickness), such that, damping layers with less or equal thickness will add low but significant damping with negligible effects on the structural properties (static deflection, natural frequency).

Fig. 3 shows the predicted variations of modal damping, natural frequency and static deflection with the aspect-ratio of the plate $(\mathrm{a} / \mathrm{h})$. As was expected, the modal damping of all plates increases at lower aspect ratios because shear prevails over flexure. Interestingly, the damping reaches a peak at very low aspect ratios and then decreases again. Intuitively, at very low aspect ratios through-the-thickness deformations will gradually prevail over shear and the effectiveness of the damping layer will be decreased. Nevertheless, the kinematic assuptions of the DLDT are not expected to be valid at the regime of very low aspect ratios because the present approach assumes negligible through-the-thickness strains. Both natural frequency and static stiffness consistently increase with lower aspect ratios.

Fig. 4 presents the variation of modal damping, natural frequency, and static deflection as functions of the FVR of the inner and outer composite sublaminates with respect to the damping layers. Fig. 4 demonstrates one unique advantage of composite laminates, that is, the additional tailoring capacity they can introduce. In both laminates, the FVR variation of the outer sublaminate has a definite effect on the modal damping of the plate. The damping increases almost linearly with the FVR, indicating that the most important composite parameter is the longitudinal modulus. Since both natural frequency and static stiffness also increase with the FVR of the outer sublaminate, the obvious choice is to have outer sublaminates of very high FVR. The modal damping is less sensitive to FVR variations of the inner sublaminate, and decreases slightly with FVR. 


\section{Summary}

This paper presented recent research developments on integrated damping mechanics for composite laminates with interlaminar damping layers. Damping mechanics for thick composite laminates and plates were developed based on a discrete-layer laminate theory. The discrete-layer displacement field of variable degrees of freedom enabled the calculation of the interlaminar shear strains in the damping layer and composite plies and the subsequent prediction of interlaminar shear damping. A semi-analytical method was developed for the prediction of the damped dynamic characteristics of composite laminates with interlaminar damping layers.

Applications on $\mathrm{Gr} / \mathrm{epoxy}$ orthotropic (unidirectional or cross-ply) composite plates with layers of damping polymers demonstrated that composite laminates have dynamic characteristics comparable to those of geometrically identical aluminum plates. In addition, composite plates with strong anisotropy variations between the restraining sublaminates exhibited potential for higher damping than geometrically equivalent aluminum plates. The effects of thickness aspect-ratio, damping layer thickness and composite fiber volume ratio on the modal damping, natural frequency, and static deflection were investigated. Overall, the results have demonstrated the potential of embedded interlaminar damping layers in composite laminates, moreover, they demonstrated the merits of the developed damping mechanics. Future studies will address the effects of damping layers on the laminate strength, buckling, and impact resistance. 


\section{REFERENCES}

1. Torvik P. J., "The Analysis and Design of Constrained Layer Damping Treatments," Damping Applications for Vibration Control, Ed. P. Torvik, ASME, N. York, 1980, pp. 27-51.

2. Schultz, A. B. and Tsai, S. W., "Measurements of Complex Dynamic Moduli for Laminated Fiber-Reinforced Composites," Journal of Composite Materials, Vol. 3, 1969, pp. 434-443.

3. Adams, R. D. and Bacon, D. G. C., "Effect of Fibre Orientation and Laminate Geometry on the Dynamic Properties of CFRP," Joumal of Composite Materials, Vol. 7, Oct. 1973, pp. 402-428.

4. Saravanos D. A. and Chamis C. C., "Mechanics of Damping for Fiber Composite Laminates Including Hygro-Thermal Effects," ALAA Journal, Vol. 28, No. 10, 1990, pp. 1813-1819.

5. Siu, C. C. and Bert, C. W., "Sinusoidal Response of Composite-Material Plates with Material Damping," ASME Joumal of Engineering for Industry, May 1974, pp. 603-610.

6. Saravanos D. A. and Chamis C. C., "Computational Simulation of Damping in Composite Structures," Journal of Reinforced Plastics and Composites, May 1991. (also, NASA TM-102567, 1990).

7. Saravanos D. A. and Chamis C. C., “A Computational Methodology for Optimizing the Passive Damping of Composite Structures," Joumal of Polymer Composites, Vol. 11, No. 6, 1990, pp. 328-336. 
8. Chen G. S. and Wada B. K., "Passive Damping for Space Truss Structures," 29th ALAA Structures, Structural Dynamics and Materials Conference, Williamsburg, Virginia, 1988, pp. 1742-1749.

9. Bronowicki A. J. and Diaz H. P., "Analysis, Optimization, Fabrication and Test of Composite Shells with Embedded Viscoelastic Layers," Proceedings of Damping '89, Feb 8-10, 1989, West Palm Beach, Florida.

10. Barrett D. J., "A Design for Improving the Structural Damping Properties of Axial Members," Proceedings of Damping '89, Feb 8-10, 1989, West Palm Beach, Florida.

11. Mantena R. P., Gibson R. F. and Shwilong H. J., "Optimal Constrained Viscoelastic Tape Lengths for Maximizing Damping in Laminated Composites," Proceedings of Damping '89, Feb 8-10, 1989, West Palm Beach, Florida.

12. Rao V. S., Sun C. T. and Sankar B. V., "Damping and Vibration Control of Some Laminated Composite Beams Using Add-On Viscoelastic Materials," Proceedings of Damping '89, Feb 8-10, 1989, West Palm Beach, Florida.

13. Murthy, P. L. N. and Chamis, C. C., "ICAN: Integrated Composite Analyzer," ALAA Paper 84-0974, May 1984.

14. Saravanos D. A. and Chamis C. C. "Unified Micromechanics of Damping for Unidirectional Fiber Composites," Joumal of Composites Technology and Research, Vol. 12, No. 1, 1990, pp. 31-40. 
15. Noor A. K. and Burton S. W., "Assessment of Computational Models for Multilayer Composite Shells," Applied Mechanics Reviews, Vol. 43, No. 4, 1990, pp. 67-96.

16. Barbero E. J., Reddy J. N and Teply J., "An Accurate Determination of Stresses in Thick Composite Laminates Using a Generalized Plate Theory," Int. Journal for Numerical Methods in Engineering, Vol. 29, 1990, pp. 1-14.

17. Drake M. L., "Damping Properties of Various Materials," $A F W A L-T R-88-4248$, March 1989. 


\section{APPENDIX}

Off-axis ply stiffness matrix $\left[E_{c}\right]$ (ref. 13):

$$
\left\{\sigma_{c}\right\}=\left[E_{c}\right]\left\{e_{c}\right\}
$$

Transformation matrices:

$$
\begin{aligned}
& {[R]=\left[\begin{array}{cccccc}
m^{2} & n^{2} & 0 & 0 & 0 & 2 m n \\
n^{2} & m^{2} & 0 & 0 & 0 & -2 m n \\
0 & 0 & 1 & 0 & 0 & 0 \\
0 & 0 & 0 & m & n & 0 \\
0 & 0 & 0 & -n & m & 0 \\
-m n & m n & 0 & 0 & 0 & m^{2}-n^{2}
\end{array}\right], \quad m=\cos \theta, \quad n=\sin \theta \text { (A2) }} \\
& {[R]^{-1}=[R(-\theta)]}
\end{aligned}
$$

On-axis damping matrix:

$$
\left[\psi_{l}\right]=\left[\begin{array}{cccccc}
\psi_{l 1} & 0 & 0 & 0 & 0 & 0 \\
0 & \psi_{l 2} & 0 & 0 & 0 & 0 \\
0 & 0 & \psi_{l 3} & 0 & 0 & 0 \\
0 & 0 & 0 & \psi_{l 4} & 0 & 0 \\
0 & 0 & 0 & 0 & \psi_{l 5} & 0 \\
0 & 0 & 0 & 0 & 0 & \psi_{l 6}
\end{array}\right]
$$

The off-axis ply damping matrix is non-diagonal and has the general form: 


$$
\left[\psi_{c}\right]=\left[\begin{array}{cccccc}
\psi_{c 11} & \psi_{c 12} & 0 & 0 & 0 & \psi_{c 16} \\
\psi_{c 21} & \psi_{c 22} & 0 & 0 & 0 & \psi_{c 26} \\
0 & 0 & \psi_{c 33} & 0 & 0 & 0 \\
0 & 0 & 0 & \psi_{c 44} & \psi_{c 45} & 0 \\
0 & 0 & 0 & \psi_{c 54} & \psi_{c 55} & 0 \\
\psi_{c 61} & \psi_{c 62} & 0 & 0 & 0 & \psi_{c 66}
\end{array}\right]
$$


Table 1. Static and dynamic characteristics of composite plates with interlaminar layers. $\left(t_{i}=0.005\right.$ in; numbers in parenthesis indicate mode order)

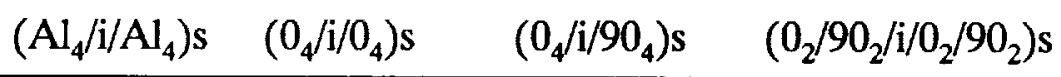

Areal Density, $10^{-3} \mathrm{Ib} / \mathrm{in}^{2}$

$\begin{array}{llll}7.95 & 4.92 & 4.92 & 4.92\end{array}$

Static Deflection (Center), in

$\begin{array}{llll}0.334 & 0.604 & 0.496 & 0.456\end{array}$

\section{Modal SDCs}

$\begin{array}{lllll}\text { Mode } 1 & 0.839(1,1) & 0.978(1,1) & 0.977(1,1) & 0.626(1,1)\end{array}$

$\begin{array}{lllll}\text { Mode } 2 & 1.656(1,2) & 0.809(1,2) & 0.421(1,2) & 1.703(1,2)\end{array}$

$\begin{array}{lllll}\text { Mode } 3 & 2.217(2,2) & 0.669(1,3) & 2.771(2,1) & 1.615(2,1)\end{array}$

Natural Frequencies, $\mathrm{Hz}$

$\begin{array}{lllll}\text { Mode 1 } & 115.7 & 119.9 & 119.9 & 124.0 \\ \text { Mode 2 } & 265.0 & 152.7 & 211.8 & 272.6 \\ \text { Mode 3 } & 395.2 & 230.1 & 354.8 & 357.7\end{array}$




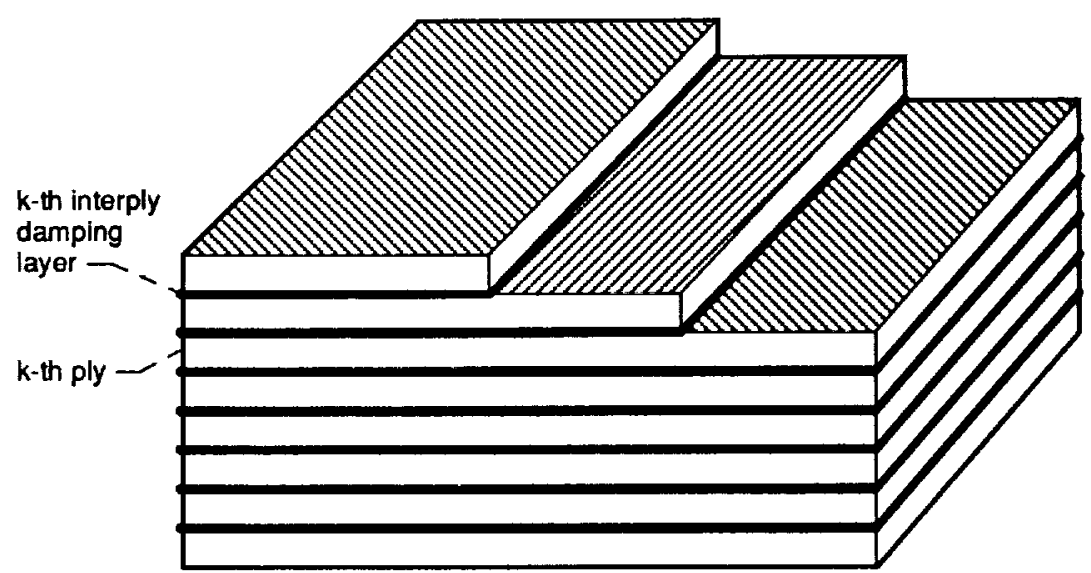

(a) Typical laminate configuration.
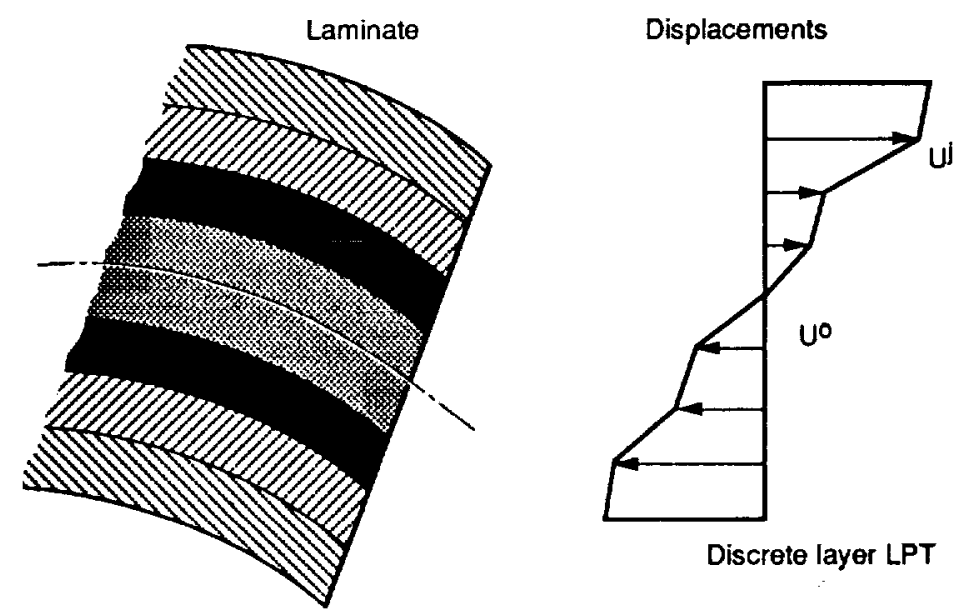

(b) Kinematic assumptions of discrete layer laminate theory

Figure 1.-Laminates with interlaminar damping layers. 

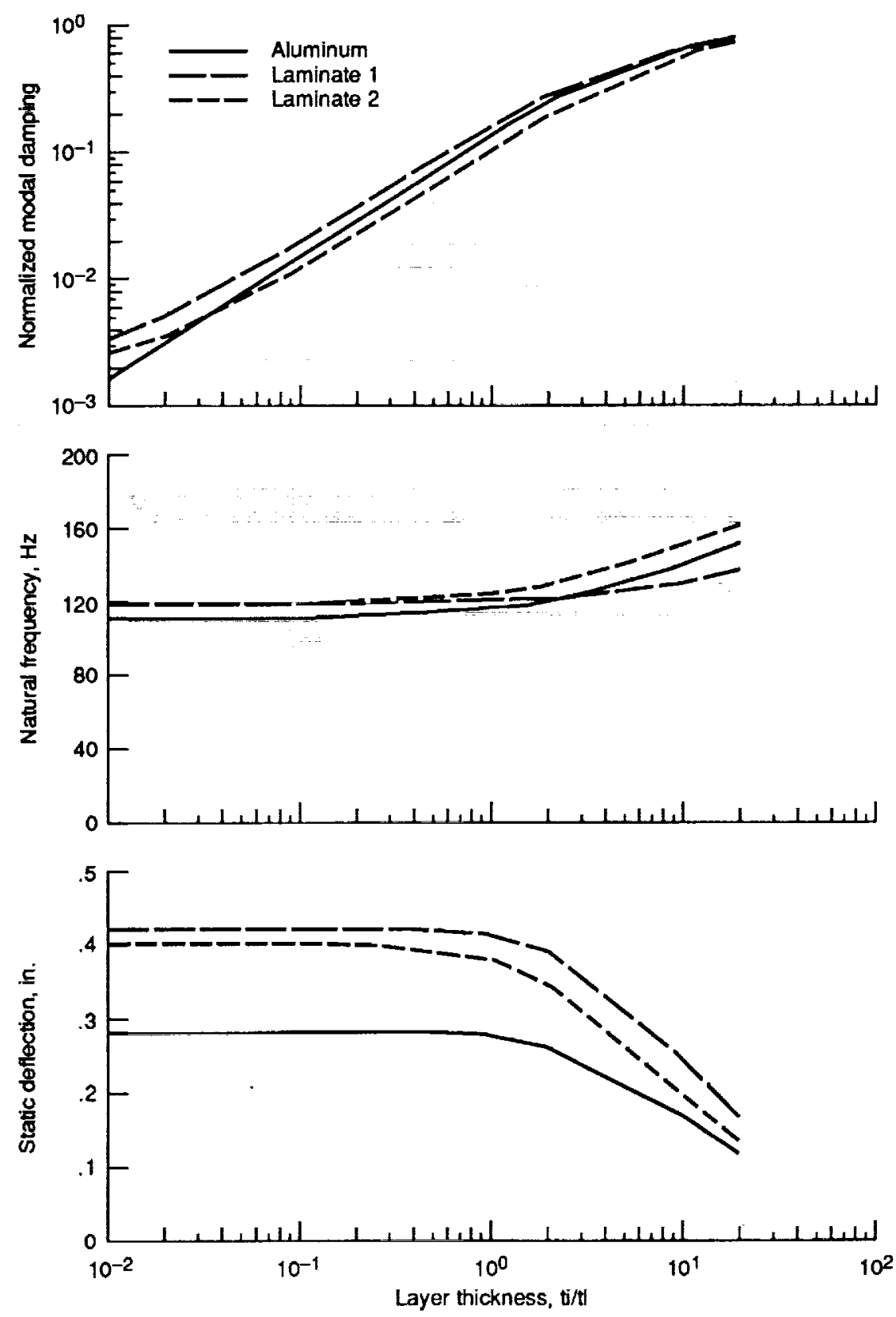

Figure 2.-Effect of damping layer thickness on static and dynamic characteristics of composite plates. Aluminum $=\left(\mathrm{Al}_{4} / \mathrm{ilAl} \mathrm{Al}_{4}\right) \mathrm{s}$; laminate $1=$ $\left(\mathrm{O}_{4} / \mathrm{N} / \mathrm{OO}_{4}\right) \mathrm{s}$; laminate $2=\left(\mathrm{O}_{2} / 90_{2} / 1 / \mathrm{O}_{2} / 90_{2}\right) \mathrm{s}$. 

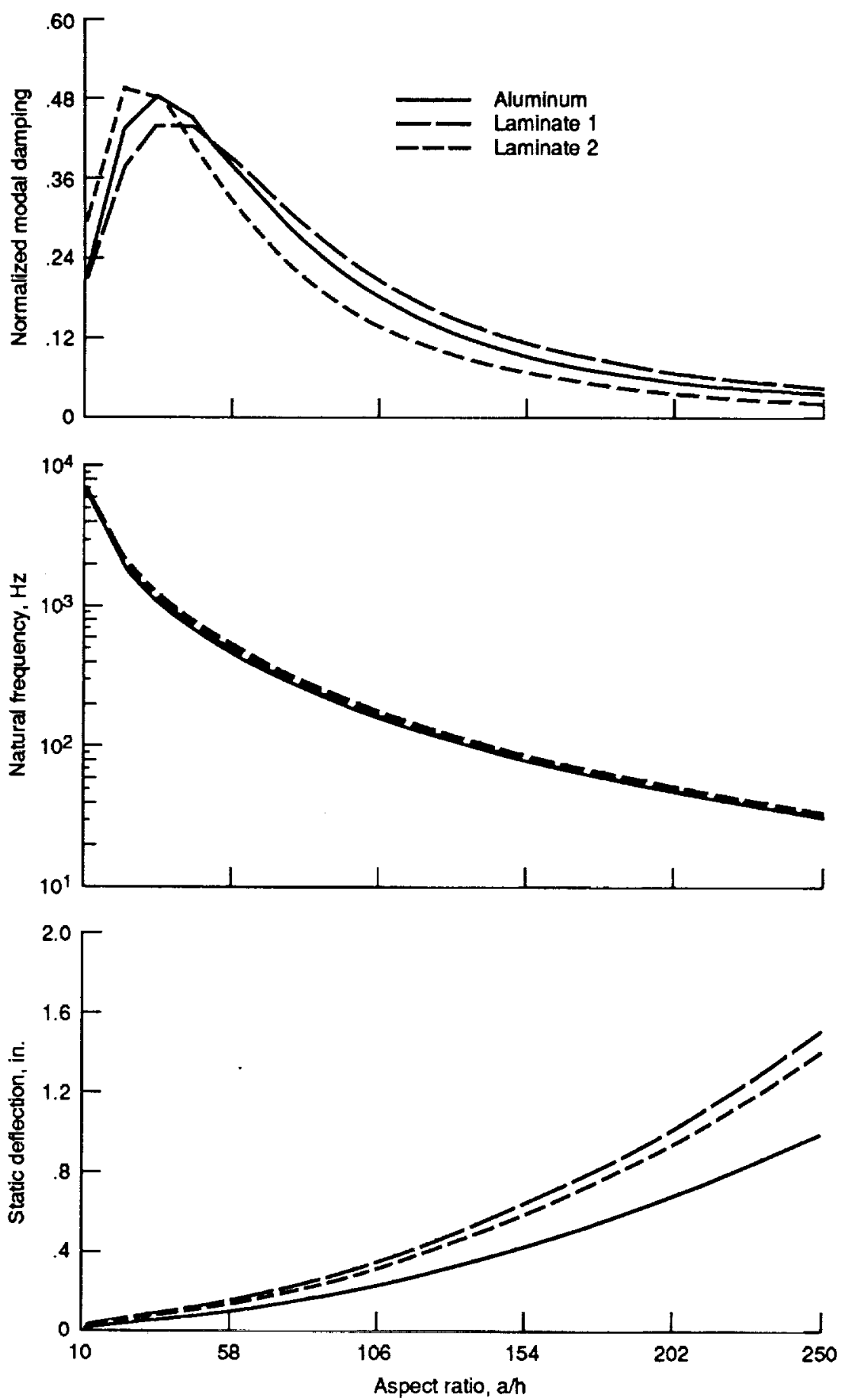

Figure 3.-Effect of plate aspect ratio on static and dynamic characteristics of composite plates. Aluminum $=\left(\mathrm{Al}_{4} / / / \mathrm{Al}_{4}\right) \mathrm{s}$; laminate $1=\left(\mathrm{O}_{4} / / \mathrm{IO}_{4}\right) \mathrm{s}$; laminate $2=\left(\mathrm{O}_{2} / 9 \mathrm{O}_{2} / 1 / \mathrm{O}_{2} / 9 \mathrm{O}_{2}\right) \mathrm{s}$. 

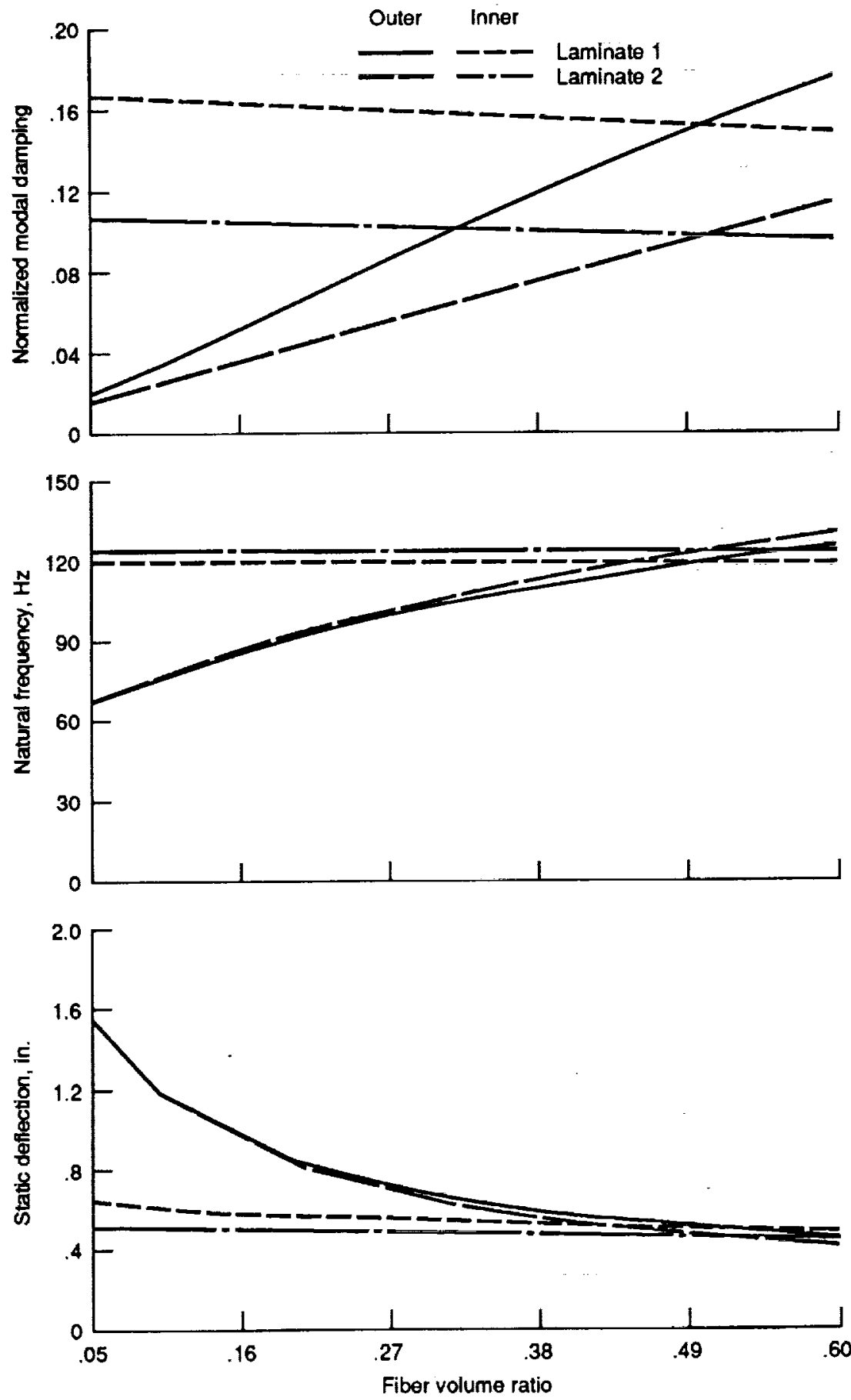

Figure 4.-Effect of fiber volume ratio on static and dynamic characteristics of composite plates. Laminate $1=\left(0_{4} / / 90_{4}\right)$ s; laminate $2=\left(0_{2} / 90_{2} / / / O_{2} / 9 O_{2}\right) s$. 
Public reporting burden for this collection of information is estimaled to average 1 hour per response, Including the time for reviewing instructions, searching existing data sources, gathering and maintaining the data needed, and completing and revlewing the collection of information. Send comments regarding this burden estimate or any other aspect of this collection of information, including surestions for reducing this burden, to Washington Headquarters Services, Directorate for information Operations and Reports, 1215 Jefferson Davis Highway, Sulte 1204, Aslington, VA 22202-4302, and to the Otfice of Management and Budget, Paperwork Reduction Project (0704-018B), Washinglon, DC 20503.

\begin{tabular}{|l|l|r|r|}
\hline 1. AGENCY USE ONLY (Leave blank) & 2. REPORT DATE & $\begin{array}{r}\text { REPOAT TYPE AND DATES COVEAED } \\
\text { Technical Memorandum }\end{array}$ \\
\hline
\end{tabular}

The Effects of Interply Damping Layers on the Dynamic Response of Composite Structures

6. AUTHOR(S)

WU-505-63-1B

D.A. Saravanos and C.C. Chamis

7. PERFORMING ORGANIZATION NAME(S) AND ADDRESS(ES)

National Aeronautics and Space Administration

Lewis Research Center

Cleveland, Ohio 44135 - 3191

8. PERFORMING ORGANIZATION REPORT NUMBER

E-6355

9. SPONSORING/MONITORING AGENCY NAMES(S) AND ADDRESS(ES)

10. SPONSORING/MONITORING AGENCY REPORT NUMBER

National Aeronautics and Space Administration

Washington, D.C. 20546-0001

NASA TM-104497

11. SUPPLEMENTARY NOTES

Prepared for the 32nd Structures, Structural Dynamics and Materials Conference cosponsored by AIAA, ASME, ASCE, AHS, and ASC, Baltimore, Maryland, April 8-10, 1991. D.A. Saravanos, Case Westem Reserve University, Cleveland, Ohio 44106 and Resident Research Associate at NASA Lewis Research Center; C.C. Chamis, NASA Lewis Research Center. Responsible person, D.A. Saravanos, (216) 433-8466.

12. DISTRIBUTION/AVAILABILITY STATEMENT

12b. DISTRIBUTION CODE

Unclassified - Unlimited

Subject Category 24

13. ABSTRACT (Maxlmum 200 words)

Integrated damping mechanics for composite laminates with constrained interlaminar layers of polymer damping materials are developed. Discrete layer damping mechanics are presented for composite laminates with damping layers, in connection with a semi-analytical method for predicting the modal damping in simply-supported specialty composite plates. Several application cases are used to demonstrate the advantages of the method. Damping predictions for graphite/epoxy composite plates of various laminations demonstrate the potential for higher damping than geometrically equivalent aluminum plates. The effects of aspect ratio, damping layer thickness, and fiber volume ratio on static and dynamic characteristics of the composite plate are also investigated.

14. SUBJECT TERMS

15. NUMBER OF PAGES

Composites; Damping; Damping layer; Laminates; Plates; Interlaminar shear damping; Model damping; Natural frequency; Static deflection.

28

16. PRICE CODE

$\mathrm{A03}$

17. SECURITY CLASSIFICATION OF REPORT

Unclassified
18. SECURITY CLASSIFICATION OF THIS PAGE Unclassified
19. SECURITY CLASSIFICATION OF ABSTAACT Unclassified 
